\title{
BMJ Open Association between direct and indirect smoking and osteoarthritis prevalence in Koreans: a cross-sectional study
}

Kyungrae Kang, Joon-Shik Shin, Jinho Lee, Yoon Jae Lee, Me-riong Kim, Ki Byung Park, In-Hyuk Ha

To cite: Kang K, Shin J-S, Lee J, et al. Association between direct and indirect smoking and osteoarthritis prevalence in Koreans: a cross-sectional study. BMJ Open 2016;6: e010062. doi:10.1136/ bmjopen-2015-010062

- Prepublication history for this paper is available online. To view these files please visit the journal online (http://dx.doi.org/10.1136/ bmjopen-2015-010062).

Received 21 September 2015 Revised 14 January 2016 Accepted 26 January 2016

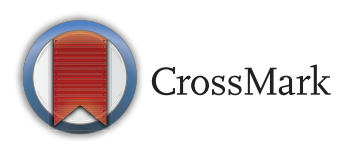

Jaseng Spine and Joint Research Institute, Jaseng Medical Foundation, Seoul, Republic of Korea

Correspondence to Dr In-Hyuk Ha; hanihata@gmail.com

\section{ABSTRACT}

Objectives: To assess the association between smoking patterns and knee and hip joint osteoarthritis $(\mathrm{OA})$ prevalence in Koreans aged 50 years or older with focus on knee $\mathrm{OA}$.

Design: Cross-sectional study using nationally representative data.

Setting: Data were collected at portable Health Examination Centres in Korea.

Participants: Data of 9064 participants of the 5th Korean National Health and Nutrition Examination Survey (2010-2012) aged 50 years or older who received knee or hip joint X-rays out of 31596 total surveyees were analysed.

Primary outcome measures: $\mathrm{OA}$ prevalence by smoking behaviour (current smoking, past smoking, indirect smoking and non-smoking).

Secondary outcome measures: Estimated risk of OA by smoking amount, period, pack-years and indirect smoking exposure time to assess the association between smoking-related factors and knee $\mathrm{OA}$ by calculating $\mathrm{ORs}$ and adjusting for covariates in a complex sampling design. A multinomial logistic regression analysis and backward elimination method was used.

Results: $0 A$ prevalence in Koreans aged 50 years or older was $13.9 \%$, with prevalence about 3.5 times higher in women (men $5.7 \%$, women $20.1 \%$ ). ORs for knee and hip joint $\mathrm{OA}$ prevalence by smoking behaviour in male indirect-smokers were lower than those in non-smokers in age and sex (OR $0.271 ; 95 \%$ $\mathrm{Cl} 0.088$ to 0.828 ), and selective adjustments (OR $0.314 ; 95 \% \mathrm{Cl} 0.102$ to 0.966 ). All other analyses for smoking behaviour and total OA prevalence, and knee $\mathrm{OA}$ prevalence were not significantly different.

Associations between smoking amount, period, packyears and knee $\mathrm{OA}$ prevalence were non-significant in ever-smokers. Associations between indirect smoking exposure time and knee OA prevalence were also nonsignificant.

Conclusions: This study found that though direct and previous smoking and $O A$ prevalence were not associated, there was a weak relationship between indirect smoking and $\mathrm{OA}$.

\section{Strengths and limitations of this study}

- The first strength of this study is that osteoarthritis $(\mathrm{OA})$ prevalence by smoking behaviour was assessed in a nationwide population survey of Koreans aged 50 years or older.

- A second strength is that it is one of the few studies to assess the relationship between $O A$ prevalence and direct and indirect smoking.

- A third strength is that $O A$ was diagnosed through both an X-ray examination and selfreport in a nationally representative sample.

- The biggest limitation of our study is that only associations between smoking and $\mathrm{OA}$ prevalence can be drawn due to its cross-sectional design.

- An additional limitation is that medication, a potential factor for $\mathrm{OA}$ prevalence, was not included for analysis.

\section{INTRODUCTION}

Osteoarthritis (OA) is a widely prevalent disorder causing pain and limitation in activity due to gradual deterioration and inflammation of articular cartilage. ${ }^{1}$ The knee joint is a frequent site of OA-related pain, ${ }^{2}{ }^{3}$ especially in older age groups where self-reported knee pain is commonly attributed to symptomatic and radiographic OA. ${ }^{4} \mathrm{~A}$ previous survey reported that up to $50 \%$ of the general population aged 50 or over suffered knee pain over the course of a year, and that $1 / 4$ had severe disabling pain. ${ }^{5}$

As life expectancy grows longer in an ageing society, the health and economic burden of knee and hip OA is expected to increase. ${ }^{6} 7$ According to the 2012 Korean National Health and Nutrition Examination Survey (KNHANES) results, OA prevalence in the Korean population aged 50 years and above was $3.3 \%$ in men and $16.0 \%$ in women, showing that prevalence was five 
times higher in women and that it steeply increased with age $(3.0 \%$ in $50 \mathrm{~s} ; 12.1 \%$ in $60 \mathrm{~s}$ and $22.2 \%$ in $70 \mathrm{~s}) .{ }^{8} \mathrm{~A}$ 2011 analysis of the US National Health and Nutrition Examination Survey (NHANES) III data found that approximately $35 \%$ of men and women aged 60 years or older had radiographic OA of the knee, ${ }^{9}$ showing a wide gap with OA prevalence in Korea, which may be due to ethnical, cultural or lifestyle differences and consequent differences in risk factors for OA. Obesity, regarded as a major risk factor for $\mathrm{OA}$ by the Organization for Economic Co-operation and Development (OECD), reportedly affects $28.5 \%$ of US men and $27.9 \%$ of women, which is the highest in OECD countries, while its prevalence in Korea (men $2.1 \%$ and women $1.6 \%$, respectively) was at the lowest levels. ${ }^{10}$ Alternatively, this disparity may reflect the difference in method of OA diagnosis.

Expenses due to OA have exceeded $1 \%$ of gross national product in England, Australia and France, ${ }^{11} 12$ and economic burden from work loss is estimated at approximately $0.11 \%$ (625 billion Korean won) of Korean gross domestic product, which is 1.5-3 times that of stroke or peptic ulcers. ${ }^{8}$ Moreover, OA is widely recognised as the most common cause of disability in elderly populations, with approximately $85 \%$ knee and hip replacements performed from OA. ${ }^{13}$

Risk factors of hip OA have not been as thoroughly investigated as those of knee OA. ${ }^{14}$ Suggested risk factors for knee OA in older adults include increased body mass index (BMI), history of knee injury, presence of Heberden's node or hand OA, female sex, older age, intense physical exercise, certain occupational activities (eg, kneeling, squatting) and increased bone mineral density, and there is limited evidence suggesting that poor mental health and hysterectomy may also be associated with onset of knee OA. ${ }^{4}$ While the association between potentially modifiable risk factors such as obesity and knee OA has been clearly established, that of obesity and hip OA is not yet well defined. Prior studies are conflicting, with some suggesting that obesity increases risk of symptomatic OA, while others state that obesity and radiographic $\mathrm{OA}$ are not significantly related. ${ }^{9}$ Although smoking is a major risk factor for several diseases including cancer, diabetes and cardiovascular disease, ${ }^{15}$ and is known to be related to elevated risk of musculoskeletal diseases such as back pain, ${ }^{16}{ }^{17}$ chronic widespread pain ${ }^{18}$ and rheumatoid arthritis, ${ }^{19-21}$ there is still considerable debate regarding the association between smoking and OA of the knee and hip joint. Anderson and Felson ${ }^{22}$ reported in an early study considering smoking as a possible risk factor for knee and hip OA that smoking had a negative relationship with OA occurrence ${ }^{23}$ and subsequent progression. ${ }^{24-27}$ However, not all results are consistent, ${ }^{28}{ }^{29}$ and evidence supporting the negative relationship between smoking and knee and hip OA development is somewhat controversial. Suggested reasons for reduced risk of knee and hip OA in smokers include decreased physical activity ${ }^{27}$ and lower body weight. ${ }^{30}$ However, these results were not maintained after adjusting for physical activity ${ }^{31}$ and body weight. ${ }^{32}$ While nicotine has been asserted to significantly increase chondrocyte proliferation both in healthy individuals and patients with knee and hip $\mathrm{OA},{ }^{33}$ some studies report that smoking is a major risk factor in knee OA pain and cartilage loss. ${ }^{34} 35 \mathrm{~A}$ recent meta-analysis of 48 observational studies encompassing over 500000 participants showed that the protective effect of smoking against knee and hip OA development is mainly true in case-control studies and especially hospital-based settings, and that the association was neutral in cohort and cross-sectional studies, especially community-based studies, which implies that the association is false negative. Furthermore, the inhibitive role of smoking in knee and hip OA occurrence was only observed in current smokers, and not in ever-smokers or ex-smokers, revealing that smoking and knee and hip OA prevalence do not display a dose-response relationship and further suggesting that a causal relationship between smoking and knee and hip OA is unlikely. ${ }^{36}$ However, there are several limitations, such as the fact that diagnostic criteria for knee and hip OA and classification of smoking behaviour differ by study, and analyses were not conducted for associations between smoking habits (smoking amount, period and pack-years) and OA prevalence. In addition, there are no studies analysing the direct relationship between indirect smoking and knee and hip joint OA prevalence.

The primary objective of this study was to investigate OA prevalence in adults aged 50 years or older by smoking behaviour (current smoking, past smoking, indirect smoking and non-smoking) using 2010-2012 KNHANES data. The secondary objective was to estimate risk of OA through assessment of smoking amount, period, pack-years and indirect smoking exposure time in patients with knee OA.

\section{METHODS}

Study population and sampling

This study used data from the 5th KNHANES survey (2010-2012). KNHANES employed a rolling sampling design that involved complex, stratified, multistage, probability cluster surveys in a representative sample of South Koreans. The survey consisted of 3 parts (health survey, health examination and nutrition survey) and was conducted by the Korean Ministry of Health and Welfare. Further information can be found in the 5th KNHANES Sample Design and the 1st to 4th Sample Design reports, available on the internet. All KNHANES data are made available through email request specifying which annual report is needed on the KNHANES website. $^{8}$

The target sample of KNHANES is South Korean civilians residing in Korea, excluding nursing home residents, active duty military personnel, convicts serving a prison sentence and foreigners. Data were collected 
through health surveys and examinations conducted at portable Health Examination Centres. In the health surveys, education and economic activity, morbidity, medical use and all nutrition survey items were assessed through interview, and health behaviour-related items included self-reported smoking and alcohol consumption. Of 31596 eligible participants in the 5th KNHANES, 24173 participants $(76.5 \%$ of the total population) answered the health examination and survey, and the data of 9064 patients aged 50 years or older who received knee or hip joint X-rays and completed health survey sections on OA and smoking were included for final analysis.

\section{Osteoarthritis}

Patients with OA were defined as: (1) participants with knee joint pain ('Have you experienced knee pain for 30 days or longer over the past 3 months?'), and a knee joint Kellgren-Lawrence (KL) grade of 2 or higher; or (2) participants with hip joint pain ('Have you experienced hip joint pain for 30 days or longer over the past 3 months?'), and a hip joint KL grade of 2 or higher. Patients meeting the knee OA self-report and knee joint $\mathrm{KL}$ grade were included for knee OA analysis.

\section{Smoking behaviour}

We divided smoking behaviour into current smoking, ex-smoking, non-smoking and indirect smoking, and included daily smoking amount, total smoking period, pack-years, and indirect smoking exposure time at work or at home as related factors.

Current smokers were defined as individuals who answered to the health survey question 'How many cigarettes have you smoked during your lifetime?', ' 5 packs (100 cigarettes) or more', and to the question 'Do you currently smoke?' that they smoked on a regular basis, and that they had smoked at least 1 cigarette within the past month. Ex-smokers were defined as individuals who answered that they had smoked 5 packs (100 cigarettes) or more in the past, but did not smoke at present. Current smokers and ex-smokers were categorised as ever-smokers and analysed for association between daily smoking amount, total smoking period, pack-years and OA prevalence. Non-smokers were defined as individuals who answered to the question 'How many cigarettes have you smoked during your lifetime?', 'Less than 5 packs (100 cigarettes) or none', and to the question 'How much are you exposed to indirect smoking at home or at work?' that they were unexposed. Individuals who had smoked less than 5 packs (100 cigarettes) or none over their lifetimes, but replied 'Yes' to either 'Are you exposed on a regular basis to indirect smoking at home?' or 'Are you exposed on a regular basis to indirect smoking at work?' were classified as the indirect smoking group, and daily exposure time to indirect smoking at home or at work was estimated through additional survey items.
Daily smoking amount was estimated from the present average daily smoking amount in current smokers and previous average daily smoking amount in ex-smokers, and divided into less than a half-pack (10 cigarettes), less than 1 pack (20 cigarettes), and 1 pack or more. Smoking period was calculated as the age difference between current age and the age that they had first smoked a whole cigarette, and divided into tertiles: $<26,<40$, and 40 years or more. Pack-years were calculated as daily smoking amount (pack) multiplied by smoking period (years), and classified by tertiles into light smoking $(<15$ pack-years), moderate smoking $(<32.4$ pack-years $)$ and heavy smoking ( $\geq 32.4$ pack-years). Indirect smoking exposure time of indirect smokers at home or at work was divided into $<1,1$ or longer, and none in non-smokers.

\section{Covariates}

Sociodemographic characteristics included age, sex, education level, income level, occupation and residential area of study participants, and health-related behaviour covered alcohol consumption, dietary habits, exercise, experience of depressive symptoms, BMI and fasting blood glucose. Education level was divided into elementary school graduation or lower, middle school graduation, high school graduation, and college graduation or higher. Graduation was assessed as of the time of study participation, and school dropouts, current attendance and leave of absence were regarded to be nongraduation. Income level was divided into quartiles (low, mid-low, mid-upper and high) according to equalised average monthly household income (average monthly household income divided by number of household members). Occupational characteristics were recategorised from the 6th revision of the Korean Standard Occupation Classification into (1) professional practice, managerial or administrative job; (2) office job; (3) service or retail industry; (4) skilled agriculture or fishery; (5) machine and equipment manufacture and operation; (6) manual labour and (7) unemployment. Residential area was divided into administrative district divisions Dong and Eup/Myeon. Eup/Myeon are divisions of rural areas, and an Eup is eligible to apply for Myeon status if it has town features and a population between 20000 and 50000 . Dong is a division of urban districts.

Regarding health behaviour-related factors, alcohol consumption was categorised by drinking frequency over the past year into less than once a month, less than 5 times a month, and 5 times a month or more. In dietary habits, individuals who had eaten 4 meals or less from 2 days previous to the date of survey were classified as irregular eaters, and those who had eaten 5 meals or more as regular eaters. The following was regarded to be adherence to regular physical exercise: (1) 3 days or more of $20 \mathrm{~min}$ exercise sessions that were highly physically taxing or required laboured breathing (eg, hiking, jogging, fast biking) during the past week; (2) 5 days or more of 30 min moderate physical exercise sessions that 
were moderately physically taxing or required slightly heavy breathing (eg, slow swimming, tennis doubles, volleyball) during the past week; or (3) 5 days or more of $30 \mathrm{~min}$ walks during the past week. BMI was analysed as a continuous variable, and fasting blood glucose was divided into binary values of $<126$ and $\geq 126 \mathrm{mg} / \mathrm{dL}$.

\section{Statistical methods}

KNHANES is a national sample survey that uses stratified cluster sampling and applies weighted values. Data were analysed with stratified, cluster and weighted variables in a complex sampling design analysis. Continuous variables are presented as mean and SE, and categorical variables as frequency and percentage (\%). Difference in characteristics by smoking behaviour was assessed by the Rao-Scott $\chi^{2}$ test or analysis of variance. Complex sampling design multinomial logistic regression analysis adjusted for covariates was conducted to calculate ORs and $95 \%$ CIs and assess the association between smoking-related factors and knee OA.

In sensitivity analysis, backward elimination was used to select significant variables for selectively adjusted models. Knee OA and knee arthritis were analysed separately, and hip joint $\mathrm{OA}$ was excluded from analysis due to the small sample size. All analyses were performed with the statistical package SAS V.9.3 (SAS Institute Inc, Cary, North Carolina, USA), and $\mathrm{p}<0.05$ was regarded to be statistically significant.

\section{Ethics, consent and permissions}

The interviewer was not given information about a participant before conducting the interview, and all participants gave written informed consent to participate.

\section{RESULTS}

OA prevalence in Koreans aged 50 years or older was $13.9 \%$, and prevalence in women was about 3.5 times higher than that in men (men $5.7 \%$, and women $20.1 \%$, respectively). OA prevalence by age group was $1.5 \%$ in men in their $50 \mathrm{~s}, 6.1 \%$ in men in their $60 \mathrm{~s}$, and $10.3 \%$ in men in their $70 \mathrm{~s}$, and $6.9 \%$ in women in their $50 \mathrm{~s}$, $20.7 \%$ in women in their $60 \mathrm{~s}$, and $36.0 \%$ in women in their 70 s, showing a sharp increase in prevalence in women of older age. The demographic and health behaviour characteristics of the study participants are listed in table 1. All factors except residential area (age, sex, income level, education level, occupation, dietary habits, alcohol consumption, exercise habits, blood glucose and BMI) showed significant differences in current, past, indirect and non-smoking. ORs for knee and hip joint $\mathrm{OA}$ prevalence by smoking behaviour adjusted for sex and age were significantly lower in male indirect smokers (OR 0.271) and in selective adjustments (OR 0.314). Although ORs of knee OA in sex and age (OR 0.273) and in selective adjustments (OR 0.321 ) in male indirect smokers were lower than those in non-smokers, they did not show a significant difference after full adjustment for all confounding variables. All other analyses for OA prevalence, and knee OA prevalence by smoking behaviour were not significantly different (table 2).

In analysis of association with smoking amount, total smoking period, pack-years and knee OA prevalence in ever-smokers (current and ex-smokers), the OR for knee OA prevalence by smoking amount, period and packyears was not significantly different (table 3 ).

Analysis of association between knee OA prevalence and indirect smoking exposure time at home or at work showed that the OR for knee OA prevalence by indirect smoking exposure time did not show a significant difference (table 4).

\section{DISCUSSION}

Data analysis of 9064 participants of the 5th KNHANES aged $\geq 50$ years revealed that smoking behaviour and knee and hip joint OA prevalence were not significantly associated. This is consistent with the results of a previous meta-analysis of 48 observational studies. ${ }^{36}$ We also confirmed that smoking amount, period, pack-years and indirect smoking exposure time at home or at work were not associated with knee OA prevalence. The sample used in this study is representative of Koreans aged 50 years or older, and the fact that knee and hip OA prevalence by smoking behaviour was assessed in a nationwide survey is a major strength of this study.

There has been continued controversy regarding the association between smoking and knee and hip OA in the existing literature. While an early cross-sectional study conducted in the USA on 5193 adults aged 3574 years demonstrated that smoking had a negative association with knee and hip OA prevalence, ${ }^{22}{ }^{23}$ later large-scale studies displayed discrepancies. For example, the Chingford study, which was conducted on 1003 females aged 45-63 years, reported that smoking and knee and hip OA prevalence did not show an inverse relationship in joints of the knee and hand joints except the distal interphalangeal joint, ${ }^{28}$ and unadjusted analyses in a cohort study assessing 2505 individuals aged 40 years or over indicated that current smokers presented significantly lower levels of knee and hip joint $\mathrm{OA}$ at all four sites investigated. However, adjusted point estimates ranged $0.60-1.48$, again suggesting that there was no association between smoking and development of knee or hip OA. ${ }^{29}$ A 2013 study on 54288 elderly Australians reported that both male and female smokers received fewer total joint replacements, which are indicative of severe knee or hip OA, ${ }^{37}$ and a later study conducted on 63257 Chinese men and women aged 4574 years residing in Singapore also reported that current smokers were less likely to undergo total joint replacement compared to non-smokers. ${ }^{38}$

Debate continues on the association between smoking and knee and hip OA prevalence in large-scale epidemiology studies and studies on the influence of smoking. 
Table 1 Characteristics of Korean adults aged 50 years or over by smoking status in Korean National Health and Nutrition Examination Survey (KNHANES) 2010-2012 $(n=9064)$

\begin{tabular}{|c|c|c|c|c|c|}
\hline & \multicolumn{5}{|l|}{ Smoking status } \\
\hline & $\begin{array}{l}\text { Current } \\
\text { smoking, n (\%) }\end{array}$ & $\begin{array}{l}\text { Past smoking, } \\
\mathrm{n}(\%)\end{array}$ & $\begin{array}{l}\text { Indirect } \\
\text { smoking, } \mathrm{n}(\%)\end{array}$ & $\begin{array}{l}\text { Non-smoking, } \\
\mathrm{n}(\%)\end{array}$ & p Value* \\
\hline \multicolumn{6}{|l|}{ Variablest } \\
\hline Age (years) (mean $\pm S E)$ & $59.5 \pm 0.3$ & $63.2 \pm 0.2$ & $59.0 \pm 0.3$ & $63.9 \pm 0.2$ & $<0.0001$ \\
\hline \multicolumn{6}{|l|}{ Sex } \\
\hline Male & $1242(31.7)$ & 2005 (51.2) & $209(5.3)$ & $457(11.7)$ & $<0.0001$ \\
\hline Female & $195(3.8)$ & $150(2.9)$ & $1022(19.8)$ & 3784 (73.5) & \\
\hline \multicolumn{6}{|l|}{ Household income } \\
\hline Low & $460(20.8)$ & $474(21.4)$ & $282(12.7)$ & $1001(45.2)$ & $<0.0001$ \\
\hline Mid-low & $358(15.9)$ & $555(24.6)$ & $310(13.7)$ & $1035(45.8)$ & \\
\hline Mid-upper & $336(14.8)$ & $544(23.9)$ & $314(13.8)$ & $1082(47.5)$ & \\
\hline High & $268(12.1)$ & $554(25.1)$ & $310(14.1)$ & 1075 (48.7) & \\
\hline \multicolumn{6}{|l|}{ Education } \\
\hline$\leq$ Elementary school graduation & $553(12.8)$ & $780(18.0)$ & $602(13.9)$ & $2398(55.3)$ & $<0.0001$ \\
\hline Middle school graduation & $287(18.5)$ & 369 (23.8) & 257 (16.6) & $637(41.1)$ & \\
\hline High school graduation & $412(19.6)$ & $604(28.8)$ & $268(12.8)$ & $816(38.9)$ & \\
\hline$\geq$ College graduation & $178(16.8)$ & $399(37.7)$ & $101(9.5)$ & $381(36.0)$ & \\
\hline \multicolumn{6}{|l|}{ Occupation } \\
\hline $\begin{array}{l}\text { Professional practice, managerial or } \\
\text { administrative job }\end{array}$ & $105(21.0)$ & $188(37.7)$ & $68(13.6)$ & $138(27.7)$ & $<0.0001$ \\
\hline Office job & $51(21.7)$ & $83(35.3)$ & $41(17.5)$ & $60(25.5)$ & \\
\hline Service or retail industry & $111(12.2)$ & $172(18.9)$ & 330 (36.3) & 296 (32.6) & \\
\hline Skilled agriculture or fishery & $259(20.0)$ & $333(25.7)$ & $173(13.4)$ & 529 (40.9) & \\
\hline $\begin{array}{l}\text { Machine and equipment manufacture } \\
\text { and operation }\end{array}$ & $242(34.0)$ & $270(38.0)$ & $102(14.4)$ & $97(13.6)$ & \\
\hline Manual labour & $165(15.8)$ & $209(20.0)$ & $227(21.7)$ & 443 (42.4) & \\
\hline Unemployment & $493(11.4)$ & $891(20.5)$ & $286(6.6)$ & 2668 (61.5) & \\
\hline \multicolumn{6}{|l|}{ Residential area } \\
\hline Dong & $978(15.0)$ & $1599(24.5)$ & $876(13.4)$ & 3075 (47.1) & 0.0732 \\
\hline Eup/Myeon & 459 (18.1) & $556(21.9)$ & $355(14.0)$ & $1166(46.0)$ & \\
\hline Body mass index $\left(\mathrm{kg} / \mathrm{m}^{2}\right)($ mean $\pm \mathrm{SE})$ & $23.4 \pm 0.1$ & $24.0 \pm 0.1$ & $24.3 \pm 0.1$ & $24.3 \pm 0.1$ & $<0.0001$ \\
\hline Fasting blood glucose (mg/dL) & $104.5 \pm 0.8$ & $105.5 \pm 0.7$ & $101.3 \pm 0.9$ & $101.6 \pm 0.5$ & $<0.0001$ \\
\hline$<126$ & $1179(15.5)$ & $1764(23.2)$ & $1083(14.2)$ & $3579(47.1)$ & $<0.0001$ \\
\hline$\geq 126$ & $188(21.0)$ & $263(29.4)$ & 95 (10.6) & $350(39.1)$ & \\
\hline \multicolumn{6}{|l|}{ Dietary habits } \\
\hline 4 meals or less during the past 2 days & $175(22.9)$ & $138(18.1)$ & $141(18.5)$ & $309(40.5)$ & $<0.0001$ \\
\hline 5 meals or more during the past 2 days & $1068(14.1)$ & $1848(24.4)$ & 1006 (13.3) & 3660 (48.3) & \\
\hline \multicolumn{6}{|l|}{ Regular physical exercise } \\
\hline No & $784(16.2)$ & 1027 (21.2) & $640(13.2)$ & 2390 (49.4) & 0.0005 \\
\hline Yes & $640(15.3)$ & $1124(26.8)$ & $588(14.0)$ & 1837 (43.9) & \\
\hline \multicolumn{6}{|l|}{ Alcohol consumption } \\
\hline Less than once a month & $424(8.2)$ & $808(15.7)$ & $754(14.7)$ & $3158(61.4)$ & $<0.0001$ \\
\hline 1-4 times a month & $368(17.9)$ & $573(27.8)$ & $328(15.9)$ & 791 (38.4) & \\
\hline 5 times a month or more & $642(35.0)$ & $765(41.8)$ & $143(7.8)$ & $282(15.4)$ & \\
\hline \multicolumn{6}{|l|}{ Experience of depressive symptoms } \\
\hline No & $1248(16.9)$ & $1922(26.0)$ & 935 (12.6) & 3291 (44.5) & $<0.0001$ \\
\hline Yes & $183(11.1)$ & $232(14.0)$ & $294(17.8)$ & $945(57.1)$ & \\
\hline
\end{tabular}

${ }^{*} p$ Value from $t$ test or Rao-Scott $\chi^{2}$ test for continuous and categorical variables.

†Continuous variables are presented as mean $\pm \mathrm{SE}$, and categorical variables are presented as $n(\%)$.

It has been reported that components of tobacco smoke have deleterious effects on chondrocyte function in intervertebral discs and inhibit extracellular matrix synthesis and cell proliferation. ${ }^{39}$ A 2007 study suggests that greater cartilage loss and more severe knee pain are sustained in men with knee OA who smoke than those who do not. ${ }^{34}$ On the contrary, a recent study indicates that normal and knee and hip OA chondrocytes both showed significantly higher mRNA and protein expression of type II collagen and increased cell proliferation at nicotine concentrations of $25-100 \mathrm{ng} / \mathrm{mL}$ compared to the control (nicotine $0 \mathrm{ng} / \mathrm{ml}){ }^{33}$

A 2011 meta-analysis on the association between smoking and knee and hip OA prevalence has suggested 
Table 2 Associations between smoking status and osteoarthritis (OA) in Korean adults aged 50 years or over in Korean National Health and Nutrition Examination Survey (KNHANES) 2010-2012

\begin{tabular}{|c|c|c|c|c|c|c|c|c|c|c|}
\hline \multirow[b]{2}{*}{ Factors } & \multirow[b]{2}{*}{ n (case) } & \multicolumn{3}{|c|}{ Adjusted for age and sex } & \multicolumn{3}{|c|}{ Fully adjusted* } & \multicolumn{3}{|c|}{ Selectively adjusted† } \\
\hline & & OR & $95 \% \mathrm{Cl}$ & p Value & OR & $95 \% \mathrm{Cl}$ & p Value & OR & $95 \% \mathrm{Cl}$ & p Value \\
\hline \multirow{2}{*}{\multicolumn{11}{|c|}{$\begin{array}{l}\text { Knee OA or hip OAf } \\
\text { All }\end{array}$}} \\
\hline & & & & & & & & & & \\
\hline Non-smoking & $4231(815)$ & 1 & & & 1 & & & 1 & & \\
\hline Current smoking & $1430(108)$ & 1.058 & 0.763 to 1.467 & 0.7350 & 1.013 & 0.683 to 1.503 & 0.9481 & 1.047 & 0.741 to 1.480 & 0.7927 \\
\hline Past smoking & $2153(148)$ & 0.726 & 0.522 to 1.010 & 0.0576 & 0.749 & 0.527 to 1.065 & 0.1072 & 0.708 & 0.506 to 0.991 & 0.0439 \\
\hline Indirect smoking & $1228(185)$ & 1.132 & 0.914 to 1.401 & 0.2555 & 1.084 & 0.847 to 1.387 & 0.5204 & 1.076 & 0.866 to 1.337 & 0.5101 \\
\hline \multicolumn{11}{|l|}{ Men§ } \\
\hline Non-smoking & 457 (34) & 1 & & & 1 & & & 1 & & \\
\hline Current smoking & $1236(69)$ & 0.903 & 0.548 to 1.486 & 0.6868 & 0.814 & 0.440 to 1.506 & 0.5114 & 0.880 & 0.525 to 1.474 & 0.6264 \\
\hline Past smoking & $2004(114)$ & 0.665 & 0.415 to 1.064 & 0.0892 & 0.694 & 0.410 to 1.175 & 0.1737 & 0.675 & 0.420 to 1.086 & 0.1053 \\
\hline Indirect smoking & $209(6)$ & 0.271 & 0.088 to 0.828 & 0.0220 & 0.391 & 0.122 to 1.260 & 0.1157 & 0.314 & 0.102 to 0.966 & 0.0434 \\
\hline \multicolumn{11}{|l|}{ Women§ } \\
\hline Non-smoking & $3774(781)$ & 1 & & & 1 & & & 1 & & \\
\hline Current smoking & $194(39)$ & 1.086 & 0.685 to 1.720 & 0.7263 & 1.187 & 0.688 to 2.048 & 0.5379 & 1.136 & 0.700 to 1.843 & 0.6055 \\
\hline Past smoking & 149 (34) & 0.613 & 0.354 to 1.061 & 0.0804 & 0.610 & 0.344 to 1.084 & 0.0923 & 0.603 & 0.347 to 1.049 & 0.0732 \\
\hline Indirect smoking & 1019 (179) & 1.209 & 0.966 to 1.513 & 0.0968 & 1.113 & 0.861 to 1.44 & 0.4136 & 1.138 & 0.905 to 1.430 & 0.2690 \\
\hline \multicolumn{11}{|l|}{ Knee OAף } \\
\hline \multicolumn{11}{|l|}{ All } \\
\hline Non-smoking & 4235 (808) & 1 & & & 1 & & & 1 & & \\
\hline Current smoking & $1430(104)$ & 1.047 & 0.752 to 1.458 & 0.7866 & 1.008 & 0.676 to 1.503 & 0.9682 & 1.033 & 0.728 to 1.467 & 0.8540 \\
\hline Past smoking & 2154 (148) & 0.737 & 0.528 to 1.028 & 0.0719 & 0.756 & 0.530 to 1.079 & 0.1239 & 0.716 & 0.510 to 1.005 & 0.0533 \\
\hline Indirect smoking & $1228(184)$ & 1.142 & 0.922 to 1.415 & 0.2231 & 1.090 & 0.850 to 1.396 & 0.4973 & 1.085 & 0.872 to 1.350 & 0.4660 \\
\hline \multicolumn{11}{|l|}{ Men§ } \\
\hline Non-smoking & 457 (34) & & & & 1 & & & 1 & & \\
\hline Current smoking & $1236(65)$ & 0.871 & 0.527 to 1.441 & 0.5918 & 0.787 & 0.423 to 1.464 & 0.4495 & 0.841 & 0.499 to 1.418 & 0.5165 \\
\hline Past smoking & $2004(114)$ & 0.665 & 0.415 to 1.065 & 0.0897 & 0.692 & 0.408 to 1.174 & 0.1724 & 0.671 & 0.416 to 1.082 & 0.1014 \\
\hline Indirect smoking & $209(6)$ & 0.273 & 0.089 to 0.837 & 0.0231 & 0.397 & 0.123 to 1.282 & 0.1226 & 0.321 & 0.104 to 0.989 & 0.0477 \\
\hline \multicolumn{11}{|l|}{ Women§ } \\
\hline Non-smoking & 3778 (774) & & & & 1 & & & 1 & & \\
\hline Current smoking & 194 (39) & 1.101 & 0.695 to 1.743 & 0.6819 & 1.208 & 0.700 to 2.085 & 0.4971 & 1.155 & 0.711 to 1.874 & 0.5609 \\
\hline Past smoking & $150(34)$ & 0.619 & 0.357 to 1.071 & 0.0864 & 0.613 & 0.343 to 1.094 & 0.0976 & 0.605 & 0.347 to 1.053 & 0.0756 \\
\hline Indirect smoking & 1019 (178) & 1.219 & 0.973 to 1.526 & 0.0848 & 1.120 & 0.865 to 1.452 & 0.3901 & 1.147 & 0.911 to 1.444 & 0.2418 \\
\hline
\end{tabular}

Logistic regression analysis.

*Adjusted for age, sex, household income, education, occupation, residential area, alcohol drinking, dietary habits, exercise habits, experience of depressive symptoms, body mass index and fasting blood glucose.

†Backward elimination method was used with significance set at $p<0.05$

†Patients with knee joint pain and knee joint Kellgren-Lawrence grade $\geq 2$ (mild) or with hip joint pain and hip joint Kellgren-Lawrence grade $\geq 2$ (mild).

$\S$ Sex was excluded in adjustments.

IPatients with knee joint pain and knee joint Kellgren-Lawrence grade $\geq 2$ (mild). 
Table 3 Associations between daily smoking amount, smoking period, pack-years and knee OA* in Korean adults aged 50 years or over in Korean National Health and Nutrition Examination Survey (KNHANES) 2010-2012

\begin{tabular}{|c|c|c|c|c|c|c|c|c|c|c|}
\hline \multirow[b]{2}{*}{ Factors } & \multirow[b]{2}{*}{ n (case) } & \multicolumn{3}{|c|}{ Adjusted for age and sex } & \multicolumn{3}{|c|}{ Fully adjusted $\dagger$} & \multicolumn{3}{|c|}{ Selectively adjusted $\ddagger$} \\
\hline & & OR & $95 \% \mathrm{Cl}$ & p Value & OR & $95 \% \mathrm{Cl}$ & p Value & OR & $95 \% \mathrm{CI}$ & p Value \\
\hline \multicolumn{11}{|l|}{ Daily smoking amount } \\
\hline \multicolumn{11}{|l|}{ All } \\
\hline None & $1224(992)$ & 1 & & & 1 & & & 1 & & \\
\hline Less than a half-pack (<10 cigarettes) & $92(66)$ & 0.992 & 0.505 to 1.951 & 0.9817 & 1.351 & 0.603 to 3.029 & 0.4649 & 1.122 & 0.524 to 2.400 & 0.7675 \\
\hline Less than 1 pack (<20 cigarettes) & $111(72)$ & 0.832 & 0.440 to 1.576 & 0.5734 & 1.140 & 0.592 to 2.195 & 0.6954 & 0.915 & 0.488 to 1.715 & 0.7827 \\
\hline 1 pack or more & $176(113)$ & 1.257 & 0.643 to 2.460 & 0.5034 & 1.102 & 0.513 to 2.365 & 0.8040 & 1.237 & 0.603 to 2.537 & 0.5614 \\
\hline \multicolumn{11}{|l|}{ Smoking period } \\
\hline \multicolumn{11}{|l|}{ All } \\
\hline None & 1224 (992) & 1 & & & 1 & & & 1 & & \\
\hline$<26$ years & $135(89)$ & 0.924 & 0.519 to 1.646 & 0.7888 & 0.921 & 0.509 to 1.668 & 0.7860 & 0.943 & 0.528 to 1.685 & 0.8436 \\
\hline$<40$ years & $97(62)$ & 1.083 & 0.501 to 2.338 & 0.8394 & 1.450 & 0.613 to 3.430 & 0.3977 & 1.181 & 0.536 to 2.605 & 0.6796 \\
\hline$\geq 40$ years & $148(101)$ & 0.947 & 0.491 to 1.825 & 0.8698 & 1.111 & 0.521 to 2.369 & 0.7846 & 0.988 & 0.484 to 2.019 & 0.9736 \\
\hline \multicolumn{11}{|l|}{ Smoking level§ } \\
\hline \multicolumn{11}{|l|}{ All } \\
\hline None & 1224 (992) & 1 & & & 1 & & & 1 & & \\
\hline Low smoking level & $137(98)$ & 0.975 & 0.541 to 1.756 & 0.933 & 1.091 & 0.567 to 2.1 & 0.794 & 1.087 & 0.583 to 2.028 & 0.7927 \\
\hline Moderate smoking level & $114(70)$ & 0.804 & 0.394 to 1.642 & 0.5501 & 1.186 & 0.562 to 2.5 & 0.6545 & 0.834 & 0.412 to 1.688 & 0.613 \\
\hline High smoking level & $127(83)$ & 1.423 & 0.688 to 2.94 & 0.3413 & 1.356 & 0.602 to 3.053 & 0.4627 & 1.421 & 0.653 to 3.093 & 0.3764 \\
\hline
\end{tabular}

Multinomial logistic regression analysis.

*Patients who met knee osteoarthritis criteria of current or ex-smokers.

†Adjusted for age, sex, household income, education, occupation, residential area, alcohol drinking, dietary habits, exercise habits, experience of depressive symptoms, body mass index and fasting blood glucose.

łBackward elimination method was used with significance set at $p<0.05$

§Low smoking level (<15 pack-years), moderate smoking level ( $<32.4$ pack-years) and high smoking level ( $\geq 32.4$ pack-years) 


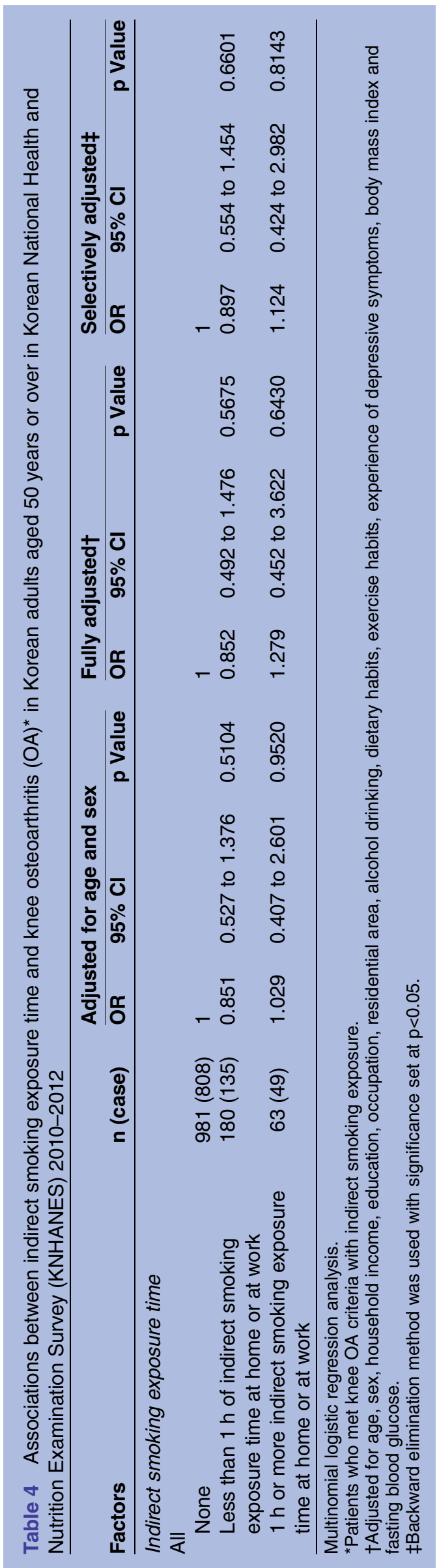

hat the 'protective' effect of smoking against knee and hip OA reported in some studies may be a false negative on the basis that this may be due to selection bias and is true mainly in hospital-based case-control studies. ${ }^{36}$ However, there are further limitations in that studies followed different criteria for OA diagnosis and did not assess knee or hip OA prevalence association by smoking habit. The results of this study show that the only significant association, which was borderline and also protective, was for men and indirect smoking (table 2). While this study categorised $\mathrm{OA}$ by $\mathrm{KL}$ grade to assess $\mathrm{OA}$ development by exposure to smoking in associations between smoking and OA, the results were not significant, which is in line with previous meta-analyses.

Analysis of indirect smoking and OA displayed sex difference with a weak association in men. $\mathrm{OA}$ is the most common cause of disability in the elderly, and women are generally known to have higher prevalence due to weaker cartilage development, and higher damage and decrease in cartilage in menopause. ${ }^{40}$ A meta-analysis of sex differences in occurrence and severity of OA found that women had more moderate radiological knee OA than men, but that there was no significant difference in hip or finger joint OA. ${ }^{41}$ The results of this study demonstrate a sex difference in OA prevalence of indirect smokers but not direct smokers, warranting further studies investigating potential mechanisms.

Similar to studies on risk factors of knee OA and hip OA, reports on aetiology also show a marked difference. Previous studies on hip OA and knee OA aetiology investigating expression of metalloproteinases consistently show that expression of the collagenase gene MMP-1 and aggrecanase genes ADAMTS- 5 and ADAMTS1 increase in knee OA and decrease in hip OA cartilage. ${ }^{42-44}$ These results suggest a different aetiology in the 2 types of OA. While this study investigated associations between smoking and knee and hip OA, drawing reference from prior studies, the sample size of patients with hip OA was too small to evaluate the association with smoking with sufficient statistical power, and results are not shown.

Indirect smoking occurs when the resulting smoke of others' cigarette smoking is breathed in, and may be divided into 'main stream smoke', inhaled and exhaled by the smoker, and 'sidestream smoke' direct from cigarette combustion. ${ }^{45}$ Of the 2 types, sidestream smoke is known to contain far more toxic substances as it does not pass through the cigarette filter or lungs of the smoker. ${ }^{46}$ It has been reported that risk of lung cancer in non-smokers exposed to indirect smoking increases by $20-30 \%$, and that of heart disease by $23 \%$. Despite reports of associations with pneumonia, bronchitis, coughing, aggravation of asthma, otitis media, macular degeneration, neurobehavioural disorder and cardiovascular disease, ${ }^{45}$ investigations on the relation between indirect smoking and OA prevalence are highly scarce. Unadjusted results partly show that indirect smoking in men has a negative relationship with OA compared to 
non-smoking. However, the association weakened in full adjustment, and analyses by indirect smoking exposure time also failed to produce significant results. Whether indirect smoking has a protective effect on $\mathrm{OA}$ and exposure time to indirect smoking was not detected as a factor due to low statistical power from small sample size in time intervals or indirect smoking and $\mathrm{OA}$ are actually unassociated is an issue warranting further study. Since this may be due to the small sample size in a crosssectional observation, these results require cautious interpretation, and further studies on the negative association between indirect smoking and $\mathrm{OA}$ in larger samples of indirect smokers are required to reach a more definite conclusion. In vivo and in vitro studies on specific pathways and byproducts of indirect and direct smoking potentially associated with OA development are also required. Moreover, trends in indirect smoking differed by gender, which is similar to the results of a previous study on gender difference in urinary cotinine levels where analyses of 3126 male and female non-smokers detected urinary cotinine levels of $3.6 \mu \mathrm{g} / \mathrm{L}$ in men and $2.9 \mathrm{\mu g} / \mathrm{L}$ in women. ${ }^{47}$ Cotinine is widely used as a marker for nicotine out of various biological markers in cigarette smoke. Approximately $70-80 \%$ of nicotine is oxidised in 2 stages in the liver and metabolised into cotinine, of which $10-15 \%$ is excreted in urine. Cotinine is commonly used as a marker of indirect smoking as its biologic half-life is long and it is not greatly influenced by urinary acidity. ${ }^{48}$ This difference by gender may be indirectly caused by environmental factors that determine exposure to indirect smoking.

Some strengths of this study include that it uses data from a national-level population survey, and data collection was conducted using standardised methods in the form of health surveys and examinations executed by skilled professionals. Also, various factors that may act as confounding variables in the association between smoking and OA prevalence (age, sex, income level, education, occupation, residential area, blood glucose, dietary habits, regular exercise regime, alcohol consumption and presence of depressive symptoms) were considered, and the backward elimination method was used for selective adjustment to increase statistical power.

The fact that OA was diagnosed through both an $\mathrm{X}$-ray examination and a self-report is another point we would like to emphasise. OA was defined as pain in the knee or hip joint, and a KL grade of 2 or higher in this study. OA prevalence in Koreans aged 50 years or older was estimated at $14.3 \%$ according to this definition in the present sample. This estimate is much lower than the OA prevalence of $35.3 \%$ in Americans aged 40 years or older based on a self-report in the NHANES raw data (1999-2008). ${ }^{49}$

We also covered smoking behaviour in more detail (daily smoking amount, smoking period, pack-years and indirect smoking exposure time) with regard to knee OA prevalence. Most previous studies classify smoking behaviour as current smoking, past smoking and nonsmoking. This study subcategorised an additional 'indirect smoking group' within the non-smoking group, indicating regular exposure to indirect smoking at home or at work, and assessed the relationship between knee OA prevalence and both direct and indirect smoking. ORs in patients with knee OA by smoking habit were also analysed for associations between smoking and knee OA prevalence.

A major limitation of this study is that only associations between smoking and knee OA prevalence can be drawn due to its cross-sectional design. Since the data are from a single assessment point, associations cannot indicate direction or causality, or dictate prognosis. Another limitation is that medication, which may influence OA prevalence, was not included for analysis. The study participants were aged 50 years or older with potential for various health issues and medication intake, including drugs known to influence OA development such as steroids or NSAIDs, and other drugs of unclear or unknown effects. Medication was regarded to be less relevant in this study due to substantial diversity in medication type, and difficulty in classification of drugs pertaining and not pertaining to OA. Validity and reliability of data may be put under question as data on smoking habits were collected by self-report, and there is the added limitation that we did not consider for indirect smoking in ever-smokers (ex-smokers and current smokers) as categorisation of smoking would not be as clear-cut as in never-smokers. Still, the fact that we differentiated between indirect and no exposure to smoking in never-smokers to distinguish additional risk factors is a notable strength of this study. Cotinine and nicotine metabolites are widely used as typical markers of cigarette smoke exposure, including indirect smoking where individuals are exposed to numerous chemical carcinogenic substances. Whereas Benowitz ${ }^{50}$ categorised smoking behaviour based on blood cotinine levels equal to or lower than the limit of detection (LOD) to be nonexposure, LOD levels up to $0.1 \mathrm{ng} / \mathrm{mL}$ to be low indirect smoking, $\quad 0.1-1.0 \mathrm{ng} / \mathrm{mL}$ to be medium indirect smoking, and $1.0-10.0 \mathrm{ng} / \mathrm{mL}$ to be high indirect smoking in a 1996 study, this study failed to assess urinary cotinine levels. Lastly, various OA-related factors other than the variables considered in the analysis may be cause for potential residual confounding. For example, while there are several studies attesting to the close relationship between $\mathrm{OA}$ and cardiovascular risk factors, ${ }^{5152}$ this study failed to consider these confounding factors.

In conclusion, analysis of associations between $\mathrm{OA}$ prevalence and smoking behaviour and habit in Koreans aged $\geq 50$ years using nationally representative data of the 5th KNHANES revealed that while direct and past smoking was not significantly associated with OA prevalence, indirect smoking and knee and hip joint OA prevalence displayed associations in men that merit further investigation. Future cohort studies on large 
numbers of indirect smokers, and studies exploring potential pathways regarding indirect smoking and OA development are indicated.

Contributors KK and I-HH conceived of and drafted the study and KK, M-rK, $\mathrm{KBP}$ and I-HH wrote the final manuscript. KK, J-SS, JL, YJL, M-rK and I-HH contributed to the study design and acquisition of the data, and made critical revisions. KBP and YJL contributed to analysis and interpretation of the data. All authors have read and approved the final manuscript.

Funding This work was supported by Jaseng Medical Foundation.

Competing interests None declared.

Ethics approval The protocol was approved by the Institutional Review Boards (IRBs) of Jaseng Hospital of Korean Medicine in Seoul, Korea (IRB approval number: KNJSIRB2015-59).

Provenance and peer review Not commissioned; externally peer reviewed.

Data sharing statement No additional data are available.

Open Access This is an Open Access article distributed in accordance with the Creative Commons Attribution Non Commercial (CC BY-NC 4.0) license, which permits others to distribute, remix, adapt, build upon this work noncommercially, and license their derivative works on different terms, provided the original work is properly cited and the use is non-commercial. See: http:// creativecommons.org/licenses/by-nc/4.0/

\section{REFERENCES}

1. Callaghan J. The adult knee. Philadelphia: Lippincott Williams \& Wilkins, 2003.

2. Urwin M, Symmons D, Allison T, et al. Estimating the burden of musculoskeletal disorders in the community: the comparative prevalence of symptoms at different anatomical sites, and the relation to social deprivation. Ann Rheum Dis 1998;57:649-55.

3. Thomas E, Peat G, Harris L, et al. The prevalence of pain and pain interference in a general population of older adults: cross-sectional findings from the North Staffordshire Osteoarthritis Project (NorStOP). Pain 2004;110:361-8.

4. Blagojevic M, Jinks C, Jeffery A, et al. Risk factors for onset of osteoarthritis of the knee in older adults: a systematic review and meta-analysis. Osteoarthr Cartil 2010;18:24-33.

5. Jinks C, Jordan K, Ong BN, et al. A brief screening tool for knee pain in primary care (KNEST). 2. Results from a survey in the general population aged 50 and over. Rheumatology (Oxford) 2004:43:55-61.

6. Juhakoski R, Heliovaara M, Impivaara O, et al. Risk factors for the development of hip osteoarthritis: a population-based prospective study. Rheumatology (Oxford) 2009;48:83-7.

7. Lawrence RC, Helmick CG, Arnett FC, et al. Estimates of the prevalence of arthritis and selected musculoskeletal disorders in the United States. Arthritis Rheum 1998:41:778-99.

8. Korean National Health and Nutrition Examination Survey. https:// knhanes.cdc.go.kr/knhanes/index.do (accessed 24 Dec 2014).

9. Nguyen US, Zhang Y, Zhu Y, et al. Increasing prevalence of knee pain and symptomatic knee osteoarthritis: survey and cohort data. Ann Intern Med 2011;155:725-32.

10. OECD Obesity Update 2014. http://www.oecd.org/health/healthsystems/theeconomicsofprevention.htm (accessed December 2015)

11. Grazio S. Osteoarthritis-epidemiology, economics and quality of life. Reumatizam 2005;52:21-9.

12. Peat G, McCarney R, Croft P. Knee pain and osteoarthritis in older adults: a review of community burden and current use of primary health care. Ann Rheum Dis 2001;60:91-7.

13. Hunter DJ, Felson DT. Osteoarthritis. BMJ 2006;332:639-42.

14. Karlson EW, Mandl LA, Aweh GN, et al. Total hip replacement due to osteoarthritis: the importance of age, obesity, and other modifiable risk factors. Am J Med 2003;114:93-8.

15. Bartecchi CE, MacKenzie TD, Schrier RW. The human costs of tobacco use (1). N Engl J Med 1994;330:907-12.

16. Deyo RA, Bass JE. Lifestyle and low-back pain. The influence of smoking and obesity. Spine 1989;14:501-6.

17. Goldberg MS, Scott SC, Mayo NE. A review of the association between cigarette smoking and the development of nonspecific back pain and related outcomes. Spine 2000;25:995-1014.
18. Andersson H, Ejlertsson G, Leden I. Widespread musculoskeletal chronic pain associated with smoking. An epidemiological study in a general rural population. Scand J Rehabil Med 1998;30:185-91.

19. Sugiyama D, Nishimura K, Tamaki K, et al. Impact of smoking as a risk factor for developing rheumatoid arthritis: a meta-analysis of observational studies. Ann Rheum Dis 2010;69:70-81.

20. Heliovaara M, Aho K, Aromaa A, et al. Smoking and risk of rheumatoid arthritis. J Rheumatol 1993;20:1830-5.

21. Albano SA, Santana-Sahagun E, Weisman MH. Cigarette smoking and rheumatoid arthritis. Semin Arthritis Rheum 2001;31: 146-59.

22. Anderson JJ, Felson DT. Factors associated with osteoarthritis of the knee in the first national Health and Nutrition Examination Survey (HANES I). Evidence for an association with overweight, race, and physical demands of work. Am J Epidemiol 1988;128:179-89.

23. Cooper $\mathrm{C}$, Inskip $\mathrm{H}$, Croft $\mathrm{P}$, et al. Individual risk factors for hip osteoarthritis: obesity, hip injury, and physical activity. Am J Epidemiol 1998;147:516-22.

24. Mnatzaganian G, Ryan P, Norman PE, et al. Smoking, body weight, physical exercise, and risk of lower limb total joint replacement in a population-based cohort of men. Arthritis Rheum 2011;63:2523-30

25. Liu B, Balkwill A, Banks E, et al. Relationship of height, weight and body mass index to the risk of hip and knee replacements in middle-aged women. Rheumatology (Oxford) 2007:46:861-7.

26. Sandmark H, Hogstedt C, Lewold S, et al. Osteoarthrosis of the knee in men and women in association with overweight, smoking, and hormone therapy. Ann Rheum Dis 1999;58:151-5.

27. Jarvholm B, Lewold S, Malchau $\mathrm{H}$, et al. Age, bodyweight, smoking habits and the risk of severe osteoarthritis in the hip and knee in men. Eur J Epidemiol 2005;20:537-42.

28. Hart DJ, Spector TD. Cigarette smoking and risk of osteoarthritis in women in the general population: the Chingford study. Ann Rheum Dis 1993;52:93-6.

29. Wilder FV, Hall BJ, Barrett JP. Smoking and osteoarthritis: is there an association? The Clearwater Osteoarthritis Study. Osteoarthr Cartil 2003;11:29-35.

30. Albanes D, Jones DY, Micozzi MS, et al. Associations between smoking and body weight in the US population: analysis of NHANES II. Am J Public Health 1987;77:439-44.

31. Vrezas I, Elsner G, Bolm-Audorff U, et al. Case-control study of knee osteoarthritis and lifestyle factors considering their interaction with physical workload. Int Arch Occup Environ Health 2010;83:291-300

32. Felson DT, Anderson JJ, Naimark A, et al. Does smoking protect against osteoarthritis? Arthritis Rheum 1989;32:166-72.

33. Ying $X$, Cheng $S$, Shen $Y$, et al. Nicotine promotes proliferation and collagen synthesis of chondrocytes isolated from normal human and osteoarthritis patients. Mol Cell Biochem 2012;359:263-9.

34. Amin S, Niu J, Guermazi A, et al. Cigarette smoking and the risk for cartilage loss and knee pain in men with knee osteoarthritis. Ann Rheum Dis 2007;66:18-22.

35. Ding C, Cicuttini F, Blizzard L, et al. Smoking interacts with family history with regard to change in knee cartilage volume and cartilage defect development. Arthritis Rheum 2007:56:1521-8.

36. Hui M, Doherty $M$, Zhang W. Does smoking protect against osteoarthritis? Meta-analysis of observational studies. Ann Rheum Dis 2011;70:1231-7.

37. Mnatzaganian G, Ryan P, Reid CM, et al. Smoking and primary total hip or knee replacement due to osteoarthritis in 54,288 elderly men and women. BMC Musculoskelet Disord 2013;14:262.

38. Leung YY, Ang LW, Thumboo J, et al. Cigarette smoking and risk of total knee replacement for severe osteoarthritis among Chinese in Singapore- the Singapore Chinese health study. Osteoarthr Cartil 2014;22:764-70.

39. Akmal M, Kesani A, Anand B, et al. Effect of nicotine on spinal disc cells: a cellular mechanism for disc degeneration. Spine 2004:29:568-75.

40. Ding C, Cicuttini F, Jones G. Tibial subchondral bone size and knee cartilage defects: relevance to knee osteoarthritis. Osteoarthr Cartil 2007:15:479-86.

41. Srikanth VK, Fryer JL, Zhai G, et al. A meta-analysis of sex differences prevalence, incidence and severity of osteoarthritis. Osteoarthr Cartil 2005;13:769-81.

42. Davidson RK, Waters JG, Kevorkian L, et al. Expression profiling of metalloproteinases and their inhibitors in synovium and cartilage. Arthritis Res Ther 2006;8:R124.

43. Kevorkian L, Young DA, Darrah C, et al. Expression profiling of metalloproteinases and their inhibitors in cartilage. Arthritis Rheum 2004;50:131-41. 
44. Swingler TE, Waters JG, Davidson RK, et al. Degradome expression profiling in human articular cartilage. Arthritis Res Ther 2009;11:R96.

45. Mackay J, Eriksen M. The tobacco Atlas. Geneva: World Health Organization, 2002

46. Hoegg U. Cigarette smoke in closed spaces. Environ Health Perspect 1972;2:117-28.

47. Heinrich J, Holscher B, Seiwert M, et al. Nicotine and cotinine in adults' urine: The German Environmental Survey 1998. J Expo Anal Environ Epidemiol 2005;15:74-80.

48. Hukkanen J, Jacob P III, Benowitz NL. Metabolism and disposition kinetics of nicotine. Pharmacol Rev 2005;57:79-115.
49. Ong KL, Wu BJ, Cheung BM, et al. Arthritis: its prevalence, risk factors, and association with cardiovascular diseases in the United States, 1999 to 2008. Ann Epidemiol 2013;23:80-6.

50. Benowitz NL. Cotinine as a biomarker of environmental tobacco smoke exposure. Epidemiol Rev 1996;18:188-204.

51. Belen E, Karaman O, Caliskan G, et al. An indicator of subclinical cardiovascular disease in patients with primary osteoarthritis: epicardial fat thickness. Int J Clin Exp Med 2015;8:9491-7.

52. Rahman MM, Kopec JA, Anis AH, et al. Risk of cardiovascular disease in patients with osteoarthritis: a prospective longitudinal study. Arthritis Care Res (Hoboken) 2013;65:1951-8. 